\title{
Interhemispheric Regulation of the Medial Prefrontal Cortical Glutamate Stress Response in Rats
}

\author{
Derek Lupinsky, Luc Moquin, and Alain Gratton \\ Douglas Hospital Research Centre and Department of Psychiatry, McGill University, Montréal, Québec H4H 1R3, Canada
}

While stressors are known to increase medial prefrontal cortex (PFC) glutamate (GLU) levels, the mechanism(s) subserving this response remain to be elucidated. We used microdialysis and local drug applications to investigate, in male Long-Evans rats, whether the PFC GLU stress response might reflect increased interhemispheric communication by callosal projection neurons. We report here that tail-pinch stress (20 min) elicited comparable increases in GLU in the left and right PFC that were sodium and calcium dependent and insensitive to local glial cystine-GLU exchanger blockade. Unilateral ibotenate-induced PFC lesions abolished the GLU stress response in the opposite hemisphere, as did contralateral $\mathrm{mGlu}_{2 / 3}$ receptor activation. Local dopamine (DA) $\mathrm{D}_{1}$ receptor blockade in the left PFC potently enhanced the right PFC GLU stress response, whereas the same treatment applied to the right PFC had a much weaker effect on the left PFC GLU response. Finally, the PFC GLU stress response was attenuated and potentiated, respectively, following $\alpha_{1}$-adrenoreceptor blockade and $\mathrm{GABA}_{\mathrm{B}}$ receptor activation in the opposite hemisphere. These findings indicate that the PFC GLU stress response reflects, at least in part, activation of callosal neurons located in the opposite hemisphere and that stress-induced activation of these neurons is regulated by GLU-, DA-, norepinephrine-, and GABA-sensitive mechanisms. In the case of DA, this control is asymmetrical, with a marked regulatory bias of the left PFC DA input over the right PFC GLU stress response. Together, these findings suggest that callosal neurons and their afferentation play an important role in the hemispheric specialization of PFC-mediated responses to stressors.

\section{Introduction}

Stressors activate several neurochemical systems in the medial prefrontal cortex (PFC), and of these, the dopamine (DA) stress response has been extensively documented (Thierry et al., 1976; Abercrombie et al., 1989). There is evidence now of hemispheric specialization in the various PFC-mediated stress responses in keeping with evidence of inherent asymmetries of cortical DA inputs (Sullivan, 2004; Gratton and Sullivan, 2005). In general, hemispheric biases in PFC DA stress responses depend on the severity, duration, and controllability of the stressor (Carlson et al., 1991, 1993; Sullivan and Szechtman, 1995; Berridge et al., 1999; Stalnaker et al., 2009). These findings suggest that the effects of different stressors and the coping responses they engage are mediated by distinct PFC mechanisms that are inherently lateralized but under DA modulation. They also imply that, in processing stressful events, the left and right PFC must somehow communicate with each other.

This idea led us to examine the role of callosal neurons. Located primarily in layers II, III, and V, these glutamate (GLU)containing pyramidal neurons send homotopically distributed projections to the opposite PFC, where they synapse on GABA interneurons and pyramidal neurons (Carr and Sesack, 1998; Karayannis et al., 2007). Importantly, DA terminals form synap-

Received March 8, 2010; revised April 20, 2010; accepted April 27, 2010.

This study was made possible by a Canadian Institutes for Health Research grant to A.G. and a Fonds de la recherche en santé du Québec doctoral fellowship to D.L.

Correspondence should be addressed to Dr. Alain Gratton, Douglas Hospital Research Center, 6875 LaSalle Boulevard, Montreal (Verdun), QC H4H 1R3, Canada. E-mail: alain.gratton@mcgill.ca.

DOI:10.1523/JNEUROSCI.1187-10.2010

Copyright $\odot 2010$ the authors $\quad 0270-6474 / 10 / 307624-10 \$ 15.00 / 0$ tic contacts with the dendrites and dendritic spines of callosal neurons (Carr and Sesack, 2000).

Stressors will also increase PFC GLU levels (Moghaddam, 1993; Bagley and Moghaddam, 1997; Steciuk et al., 2000), although it is unclear which of the known GLU inputs to PFC is responsible for this response. The exact nature of the PFC GLU stress response also remains to be fully elucidated; there is some debate as to whether this response is due to increased GLU release from neurons or from glial cells. While evidence that neurons contribute significantly to stress-induced increases in PFC GLU has been reported (Moghaddam, 1993), some have argued otherwise (Timmerman and Westerink, 1997; Timmerman et al., 1999) (but see van der Zeyden et al., 2008).

In the present study, we first documented possible hemispheric differences in the PFC GLU stress responses and, in doing so, established the extent to which this response reflects increased neuronal transmitter release. Next we investigated how the left and right PFC GLU stress responses are altered by excitotoxic lesions to the opposite PFC and, from this, examined whether the PFC GLU stress response requires activation of a GLU input to the opposite hemisphere. We then sought to determine whether the left and right PFC GLU stress responses are differentially regulated by the DA input to the opposite PFC. Finally, we examined the possibility that the PFC GLU stress response is regulated by GABA- and norepinephrine (NE)-sensitive mechanisms in the opposite PFC. In the case of GABA, the rationale here rests on evidence that the PFC DA stress response is modulated locally by GABA (Doherty and Gratton, 1999) and that the activity of pyramidal neurons is regulated both by GABA- and DA-sensitive mechanisms (Seamans et al., 2001; Trantham-Davidson et al., 
2004; Tseng and O'Donnell, 2004). The rationale for investigating the role of NE is based on evidence that stressors activate PFC NE transmission (Finlay et al., 1995) and that the nucleus accumbens DA stress response is indirectly modulated by PFC NE (NicNiocaill and Gratton, 2007).

\section{Materials and Methods}

Animals

Adult male (300-400 g) Long-Evans rats (Charles River) were used. The animals were singly housed on a reverse $12 \mathrm{~h}$ light/dark cycle (lights off at 12:00 P.M.) with food and water available ad libitum. All procedures were approved by McGill's University Animal Care Committee in accordance with the guidelines of the Canadian Council on Animal Care.

\section{Surgery}

Animals were pretreated with atropine sulfate $(0.1 \mathrm{mg} / \mathrm{kg}$, i.p.), anesthetized with sodium pentobarbital $(54.7 \mathrm{mg} / \mathrm{kg}$, i.p.), and stereotaxically implanted with a 22 gauge stainless steel guide cannula (Plastics One) into either the left or right PFC at the following flat skull coordinates (Paxinos and Watson, 1996): anteroposterior (AP): $3.2 \mathrm{~mm}$ anterior to bregma, mediolateral (ML): $\pm 0.6 \mathrm{~mm}$ off midline, dorsoventral (DV): $2.2 \mathrm{~mm}$ below dura. This cannula would later be used to insert the microdialysis probe into the PFC target site. The cannula was secured with acrylic dental cement anchored to four screws threaded into the cranium. An obturator that extended $3.0 \mathrm{~mm}$ beyond the tip of the guide cannula was inserted to prevent infection and CSF seepage. The incision was closed with monofilament sutures and antibiotic powder (Cicatrin; neomycin sulfate: $3300 \mathrm{IU}$ ) applied to the wound. Carprofen ( $5 \mathrm{mg} / \mathrm{kg}$, s.c.) was used for postoperative analgesia (once daily for $2 \mathrm{~d}$ ). Animals were allowed 3-4 d to recover before testing.

In one set of experiments, animals received a unilateral excitotoxic or sham lesion to the left or right PFC $10 \mathrm{~d}$ before being implanted with a microdialysis probe guide cannula into the opposite, intact PFC. A $0.5 \mu \mathrm{l}$ volume of ibotenic acid solution ( $5 \mu \mathrm{g} / \mu \mathrm{l}$; Sigma) or its saline vehicle (sham lesions) was microinjected into each of two adjacent sites within the left or right PFC at the following coordinates: AP: $+3.5 \mathrm{~mm}$, ML: $\pm 0.7 \mathrm{~mm}, \mathrm{DV}:-4.7 \mathrm{~mm}$; and AP: $+2.5 \mathrm{~mm}, \mathrm{ML}: \pm 0.7 \mathrm{~mm}, \mathrm{DV}:-3.5$ $\mathrm{mm}$. Solutions were slowly injected at a rate of $0.1 \mu \mathrm{l} / \mathrm{min}$ from the tip of a $1 \mu \mathrm{l}$ Hamilton microsyringe that was stereotaxically lowered into the brain. Following injection, the microsyringe was left in place for 2-3 min to allow diffusion of the solution. Bore holes were sealed with bone wax. These animals were housed singly until cannula implantation.

For those experiments involving central drug microinjections, animals were also implanted with a 27 gauge stainless steel guide cannula (Plastics One) aimed at the opposite infralimbic PFC; that is, contralateral to the microdialysis guide cannula. This cannula was lowered into the PFC at a $30^{\circ}$ angle off the anteroposterior plane using the following coordinates: AP entry point: $+0.7 \mathrm{~mm}$, ML: $\pm 0.6 \mathrm{~mm}, \mathrm{DV}:-2.2 \mathrm{~mm}$. An obturator was inserted in this cannula as well.

\section{Microdialysis probes}

We used I-shaped, microdialysis probes comprised of side-by-side fused silica inlet-outlet lines [internal diameter (ID): $50 \mu \mathrm{m}$ ] that were encased in polyethylene tubing (ID: $0.58-0.38 \mathrm{~mm}$ ). A length of regenerated, hollow cellulose membrane (Spectrum, molecular weight cutoff: 13 $\mathrm{kDa}, \mathrm{OD}: 216 \mu \mathrm{m}$; ID: $200 \mu \mathrm{m}$ ) was secured to the end of a stainless steel cannula (26 gauge) using cyanoacrylate adhesive and was sealed at its tip with epoxy; the active membrane measured $2.5 \mathrm{~mm}$. A stainless steel collar fitted to the probes provided a secure, threaded connection to the animals' indwelling guide cannula. The probe assembly was affixed to a stainless steel spring that was tethered to a liquid swivel (CMA). Probes were calibrated in artificial CSF (aCSF) containing $100 \mathrm{ng} / \mathrm{ml}$ aspartate, GLU, and GABA. In vitro probe recovery ranged from 14 to $19 \%$ at a flow rate of $2 \mu \mathrm{l} / \mathrm{min}$. Computer-controlled microinfusion pumps (CMA) were used to deliver perfusate to the probes, and the dialysate was collected from the fused silica outlet line (dead volume: $0.79 \mu \mathrm{l}$ ).

\section{Testing procedures}

Microdialysis. Animals were tested in opaque circular (30 cm diameter) chambers containing $2 \mathrm{~cm}$ of bedding. The animals had ad libitum access to food and water and were acclimatized to the chamber for $4 \mathrm{~h}$ before the first test day. On the day of testing, a microdialysis probe was inserted into the animals' indwelling guide cannula and perfused with sterile, degassed aCSF (26 mm NaHCO $3,3 \mathrm{~mm} \mathrm{NaH}_{2} \mathrm{PO}_{4}, 1.3 \mathrm{~mm} \mathrm{MgCl}_{2}, 2.3 \mathrm{~mm}$ $\mathrm{CaCl}_{2}, 3.0 \mathrm{~mm} \mathrm{KCl}, 126 \mathrm{~mm} \mathrm{NaCl}, 0.2 \mathrm{~mm}$ L-ascorbic acid) at a rate of 1.5 $\mu \mathrm{l} / \mathrm{min}$ throughout the $4 \mathrm{~h}$ stabilization period. One hour before testing, the flow was increased to $2 \mu \mathrm{l} / \mathrm{min}$. Dialysate samples were collected during this period but were discarded; this served to habituate the animals to the collection process and the presence of the experimenter. Samples were then taken at $10 \mathrm{~min}$ intervals for $1 \mathrm{~h}$ before, during, and for $2 \mathrm{~h}$ after a $20 \mathrm{~min}$ exposure to tail-pinch stress, which consisted of securing a plastic-covered metallic clip $2 \mathrm{~cm}$ from the base of the animals' tail; this was comprised of an alligator clip the teeth of which were flattened and covered by a length of shrink tubing to prevent injury to the animals' tail. Freezing behavior, vocalization, and defecation was typically observed during the 20 min episode of tail-pinch stress. Most animals also engaged in sporadic bouts of gnawing on the plastic-covered metallic clip; in our previous studies, this relatively mild stressor consistently elicited robust increases in extracellular PFC DA levels (Brake et al., 2000; Stevenson et al., 2003). Each $20 \mu$ l dialysate sample was collected in a fraction vial preloaded with $1 \mu \mathrm{l}$ of $0.25 \mathrm{M}$ perchloric acid to prevent analyte degradation and immediately stored at $4^{\circ} \mathrm{C}$ for subsequent analysis.

Reverse dialysis. Reverse dialysis was used to study the effects of locally perfused treatments on basal and stress-induced increases in extracellular GLU levels. The aim of these experiments was to confirm that the PFC GLU stress responses are due to increased synaptic release of the transmitter. The sodium channel blocker-tetrodotoxin (TTX with citrate, 10 $\mu \mathrm{M}$, Alomone Labs) — was used to determine whether stress-induced increases in PFC GLU were derived from an impulse-dependent neuronal pool. The calcium dependency of PFC GLU stress responses was also tested by replacing aCSF $\mathrm{CaCl}_{2}$ with an equimolar concentration $\mathrm{MgCl}_{2}$ (final concentration: $3.6 \mathrm{~mm}$ ). A possible contribution of non-neuronal GLU to the stress response was examined by locally perfusing $(S)-4$ carboxyphenylglycine (CPG, $50 \mu \mathrm{M}$, Tocris Bioscience), a glial cystineglutamate exchanger blocker (Baker et al., 2002; Melendez et al., 2005). At $30 \mathrm{~min}$ before onset of tail-pinch stress, the aCSF perfusate was changed to aCSF containing one of the above three treatments using a liquid switch (CMA) and was maintained throughout the 20 min stress episode and subsequent recovery period. The three perfusate conditions were tested in separate groups of animals. Animals were each tested on separate days under both the control (aCSF) and one of the three perfusate conditions (TTX, $\mathrm{Ca}^{2+}$-free aCSF, or CPG). The treatment order was counterbalanced across animals, and at least $5 \mathrm{~d}$ separated the two tests; a fresh dialysis probe was used for each test.

Local drug microinjections. Each animal received a drug and vehicle control treatment. All drugs were dissolved in aCSF on the test day, and the treatment order was counterbalanced across animals with at least $5 \mathrm{~d}$ separating each treatment; a fresh dialysis probe was used on each treatment day. A $0.5 \mu \mathrm{l}$ volume of solution was slowly ejected over $5 \mathrm{~min}$ from the tip of a 30 gauge cannula that was connected to a Hamilton microsyringe by a length of polyethylene tubing such that the tip extended $2 \mathrm{~mm}$ beyond the animals' indwelling guide cannula and into the PFC target site. A sample was collected $10 \mathrm{~min}$ after injection just before the onset of the stress episode and stored as described above.

Given evidence of hemispheric asymmetries in the PFC DA stress response, stress-induced increases in GLU levels were sampled in either the left or right $\mathrm{PFC}$ following local $\mathrm{D}_{1}$ receptor blockade in the opposite PFC with SCH 23390 hydrochloride (6 or 0.06 nmol; Sigma). For all subsequent experiments stress-induced increases in GLU levels were monitored in the right PFC following drug microinjections into the left PFC. The following drugs were tested: (1) LY379268, a group II metabotropic glutamate receptor $\left(\mathrm{mGluR}_{2 / 3}\right)$ agonist (10 nmol; Tocris Bioscience), (2) benoxathian (BENOX), an $\alpha_{1}$-adrenoreceptor antagonist (10 nmol; Sigma), and (3) $R(+)$-baclofen $\mathrm{HCl}$, a $\mathrm{GABA}_{\mathrm{B}}$ receptor agonist (10 nmol; Sigma). 


\section{HPLC}

Glutamate levels were determined by precolumn derivatization using HPLC with electrochemical detection (HPLC-EC). The chromatographic system consisted of an ESA pump (model 582) and an ESA injector (model 542) coupled to a Waters Xterra MS C18 3.0 $\times 50 \mathrm{~mm} 5$ $\mu \mathrm{m}$ analytical column. The mobile phase was prepared as needed and consisted of $3.5 \%$ acetonitrile, $20 \%$ methanol, and $100 \mathrm{~mm}$ sodium phosphate dibasic $\left(\mathrm{Na}_{2} \mathrm{HPO}_{4}\right)$ adjusted to $\mathrm{pH} 6.7$ with $85 \%$ phosphoric acid. The flow rate was set at $0.5 \mathrm{ml} / \mathrm{min}$, and the electrochemical detector (ESA Coularray, model no. 5600A) was set at potentials of $+150 \mathrm{mV}$ and $+550 \mathrm{mV}$.

Working standards $(100 \mathrm{ng} / \mathrm{ml})$ and derivatization reagents were prepared fresh daily from stock solutions and loaded with samples into a refrigerated $\left(10^{\circ} \mathrm{C}\right) \mathrm{ESA}$ autosampler (model 542). Before injection onto the analytical column, each fraction was sequentially mixed with $20 \mu \mathrm{l}$ of $o$-phthaldehyde $(0.0143 \mathrm{~mol} / \mathrm{L})$ diluted with $0.1 \mathrm{M}$ sodium tetraborate and $20 \mu \mathrm{l}$ of 3-mercaptopropionic acid $(0.071 \mathrm{~mol} / \mathrm{L})$ diluted with $\mathrm{H}_{2} \mathrm{O}$ and allowed to react for $5 \mathrm{~min}$. Following each injection, the injection loop was flushed with $20 \%$ methanol to prevent contamination of subsequent samples. Under these conditions, the retention time for GLU was $\sim 2.4 \mathrm{~min}$ with a total run time of $30 \mathrm{~min} / \mathrm{sample}$. Chromatographic peak analysis was accomplished by identification of unknown peaks in a sample matched according to retention times from known standards using ESA's CoulArray software.

\section{Histology}

Animals were deeply anesthetized with sodium pentobarbital $(70 \mathrm{mg} / \mathrm{kg}$, i.p.) and perfused transcardially with $0.9 \%$ heparinized saline, followed by a $4 \%$ paraformaldehyde solution. The brains were extracted and stored in $4 \%$ paraformaldehyde and subsequently cryoprotected in a $30 \%$ sucrose solution before being sliced. Lesion sites and probe and microinjector tip placements were confirmed from $30 \mu \mathrm{m}$ thioninstained coronal sections.

\section{Data format and statistical analyses}

Unless stated otherwise, the data are expressed as the mean $( \pm$ SEM) percentage change in GLU levels relative to the pooled average of the five baseline samples collected immediately before central drug injection and/or stress; the data were not corrected for the probes' in vitro recovery. Treatment effects were tested for statistical significance using a repeated measures ANOVA using the appropriate two- or three-factorial design with time as a within-group factor and treatment and, in some cases, hemisphere, as between-group factors. When indicated, post hoc comparisons were performed using Tukey's honestly significant difference test $(\alpha=0.05)$. Analyses were performed using Datasim software (version 1.2, Drake R. Bradley, Bates College, Lewiston, ME).

\section{Results}

A total of 86 animals with histologically confirmed PFC cannula and microdialysis probe placements were included in the study (ibotenic acid lesion experiment: $n=28$; TTX experiment: $n=6$; $\mathrm{Ca}^{2+}$-free aCSF experiment: $n=6$; CPG experiment: $n=7$; LY379268 experiment: $n=6$; SCH23390 experiment: $n=20$; BENOX experiment: $n=7$; baclofen experiment: $n=6$ ). As can be seen in Figure 1, the active $(2.5 \mathrm{~mm})$ segment of the dialysis probes spanned the ventral-dorsal extent of the infralimbic PFC (IL-PFC) and prelimbic PFC (PL-PFC), and in all cases, damage produced by the tips of the injection cannulae was found to extend into the IL-PFC target site.

\section{Left versus right PFC GLU stress responses}

Figure 2 is a comparison of the stress-induced increases in GLU levels observed in left and right PFC. The data shown in Figure $2 B$ are the averaged percentage changes in GLU levels observed in the left $(n=10)$ and right $(n=28)$ PFC of those animals that received control vehicle microinjections into the opposite PFC before being stressed. Two findings emerged from this analysis.
A

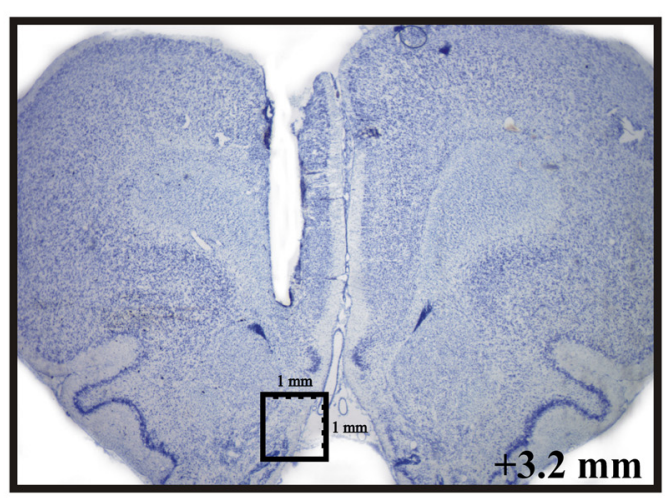

B

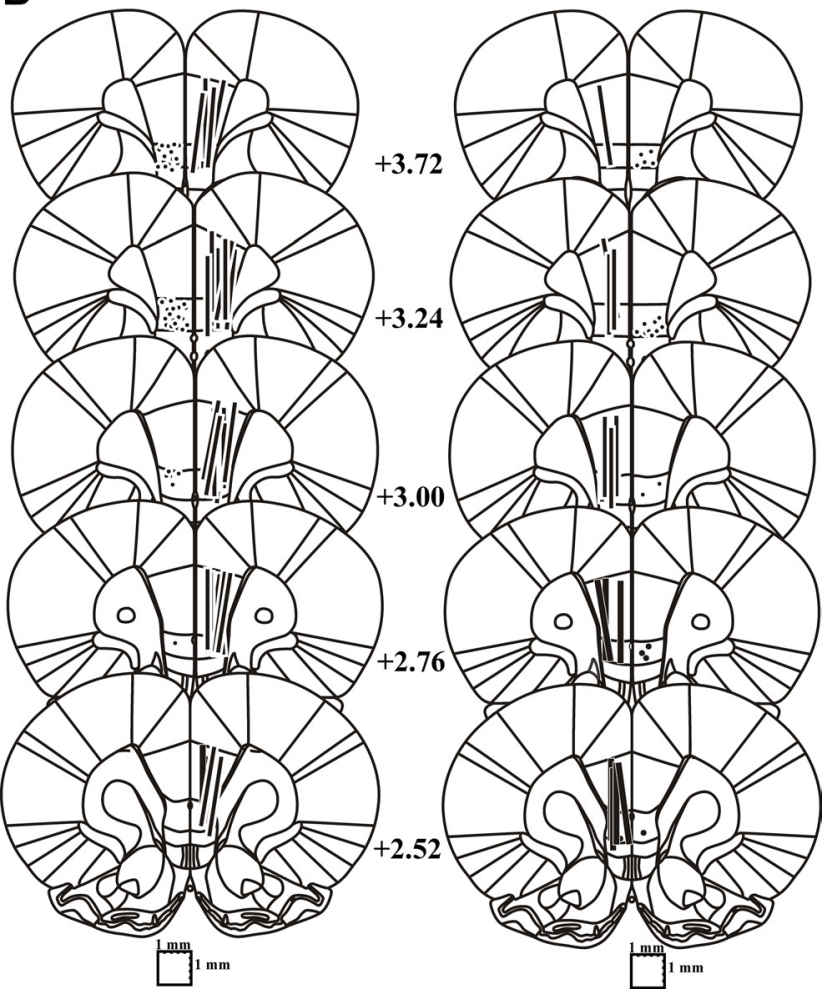

Figure 1. $\quad A, B$, Histological verification of $\mathrm{PFC}$ microdialysis probe and injection cannula placements. $\boldsymbol{A}$, Photomicrograph of typical damage produced by PFC microdialysis probe. $B$, Schematic reconstruction of microdialysis probe (vertical bars) and injection cannula (filled circles) placements within the IL-PFC. Length of vertical bars corresponds to the length of the active portion of the dialysis membrane $(2.5 \mathrm{~mm})$.

First, there were no significant hemispheric differences in the magnitude of stress-induced increases in PFC GLU levels. Second, GLU levels in both the left and right PFC increased significantly above basal levels not only during the 20 min tail-pinch stress episode (10 and 20 min time points) but also immediately before stress onset ( 0 min time point). This initial rise in GLU levels was associated with the ( $5 \mathrm{~min})$ microinjection procedure performed shortly after collecting the last baseline sample $(-10$ min time point). Although repeatedly handled and acclimatized before each experiment, animals had to be briefly immobilized to insert the microinjector into their guide cannula, and this, apparently, was sufficiently stressful to stimulate GLU efflux. This explanation is supported by the fact that no such early increase in GLU levels was seen when animals were not in any way manipulated before tail-pinch stress as was the case with the sham- 

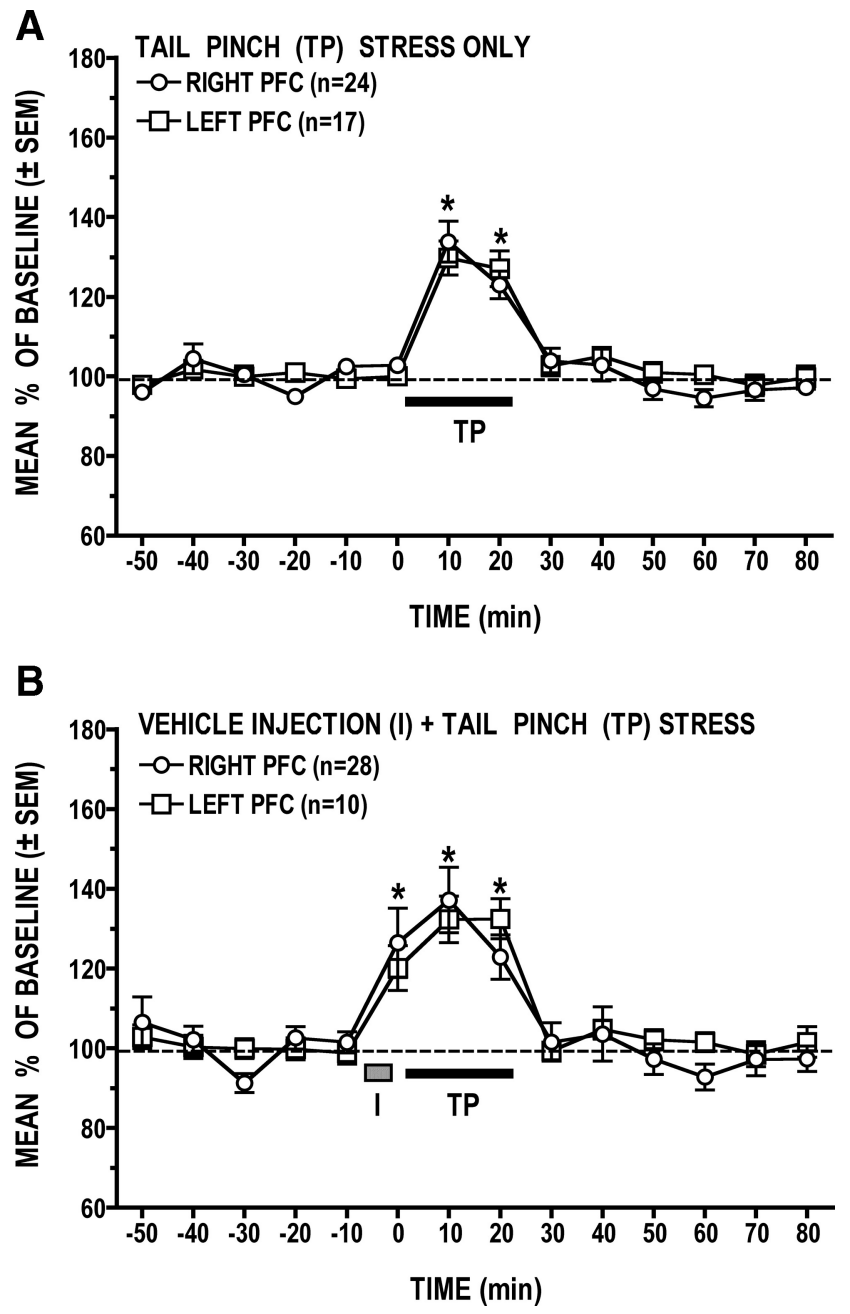

Figure 2. $A, B$, Comparison of stress-induced increases in left versus right PFC dialysate levels of GLU. $A$, Comparable increases in GLU levels were elicited in the left and right PFC during tail-pinch (TP) stress. $\boldsymbol{B}$, Significant increases in GLU levels were also elicited in both hemispheres as animals were handled during the vehicle microinjection procedure (I) that preceded tail-pinch stress. In this and subsequent figures, the length of the black bar and of the shaded rectangle correspond to the duration, respectively, of the tail-pinch stress episode ( $20 \mathrm{~min}$ ) and of the microinjection procedure. ${ }^{*} p<0.05$ versus prestress baseline.

lesioned animals that served as controls for the ibotenatelesioned animals. As can be seen in Figure $2 \mathrm{~A}$, increases in GLU levels were seen only during the 20 min tail-pinch stress episode, but here too, there were no significant hemispheric differences in the magnitude of the GLU stress response. We also compared basal dialysate levels of GLU in the left and right PFC. This was done by pooling and averaging the absolute GLU levels in the first five prestress dialysate samples. The analysis revealed that basal PFC GLU levels in the right (mean \pm SEM $=0.452 \pm 0.036$ $\mathrm{pmol} / \mu \mathrm{l})$ and left $(0.372 \pm 0.027 \mathrm{pmol} / \mu \mathrm{l})$ hemispheres did not differ significantly $\left(t_{(359)}=1.68, p=0.0942\right)$.

\section{Effects of TTX, $\mathrm{Ca}^{2+}$-free aCSF, and CPG}

Figure $3 A$ shows that the PFC GLU response to tail-pinch stress is significantly attenuated by sodium channel blockade with TTX (treatment $\times$ time interaction: $F_{(13,65)}=2.86, p=0.0026$ ). Post hoc analysis revealed that the peak GLU stress response seen (at 20 min) during local perfusion of the aCSF vehicle was all but abolished by TTX $(p<0.05)$, indicating that the stress-induced in-
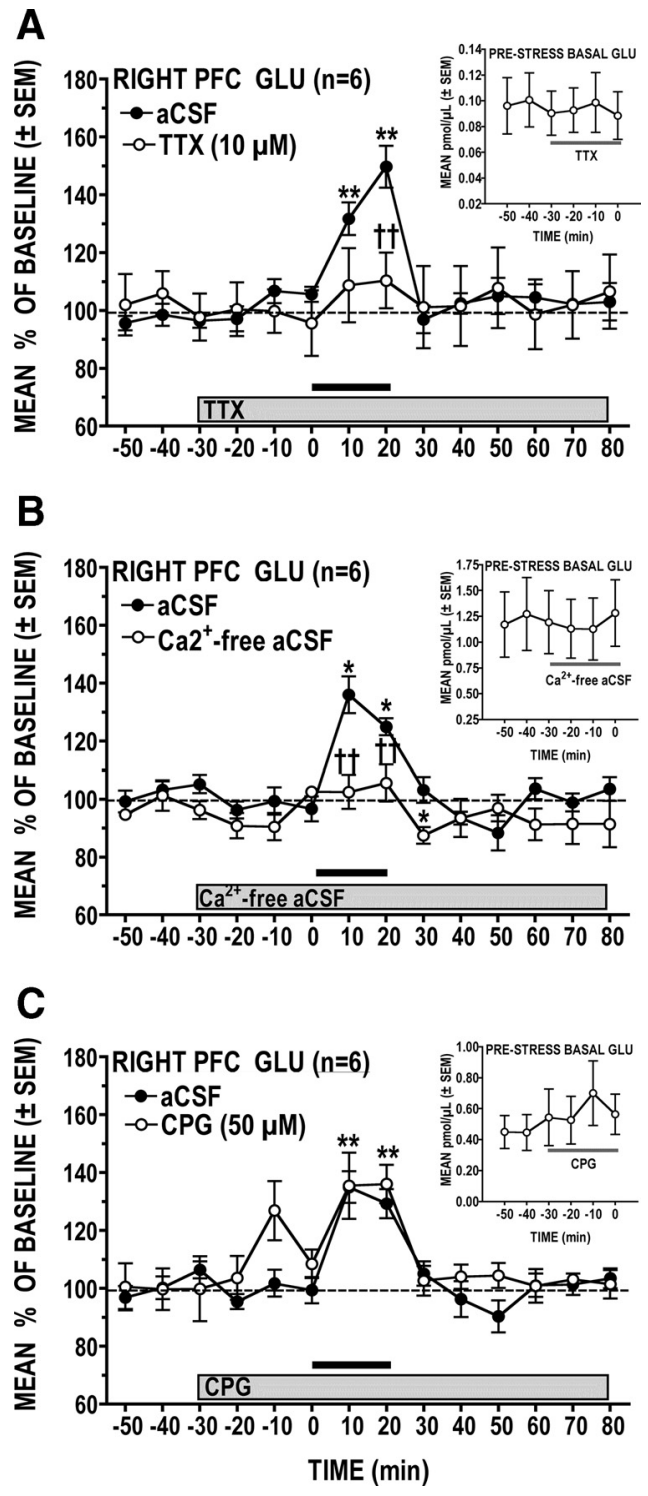

Figure 3. $A-C$, Effects of locally perfused TTX $(\boldsymbol{A}), \mathrm{Ca}^{2+}$-free aCSF $(\boldsymbol{B})$, and CPG $(\boldsymbol{C})$ on stress-induced increases in PFC GLU levels. Insets show absolute levels of basal (prestress) GLU before and during locally perfused treatment. $A$, Sodium channel blockade with TTX significantly attenuated the GLU response to tail-pinch stress but did not affect basal GLU levels. $\boldsymbol{B}, \mathrm{A}$ significantly attenuated GLU stress response was also observed when the perfusate was switched to $\mathrm{Ca}^{2+}$-free aCSF; basal GLU levels were unaffected. C, Glial cystine-GLU antiporter blockade with CPG had no effect on the GLU response to stress but did produce a transient increase in basal GLU levels. ${ }^{*} p<0.05,{ }^{* *} p<0.01$ versus prestress baseline; ${ }^{{ }^{* \dagger}} p<0.01$ versus time-matched vehicle control.

creases in extracellular PFC GLU reflects primarily transmitter release from an impulse-dependent neuronal pool. Interestingly, TTX had no effect on basal (prestress) dialysate levels of GLU (Fig. 3A, inset). The PFC GLU stress response was similarly attenuated when samples were collected using a $\mathrm{Ca}^{2+}$-free aCSF perfusate (Fig. $3 B$ ) (treatment $\times$ time interaction: $F_{(13,65)}=3.34$, $p<0.001, n=6$ ), and as was the case with TTX, there was no effect of this condition on basal (prestress) levels of GLU (inset). Finally, as can be seen in Figure $3 C$, locally applied CPG had no effect on the GLU stress response $(p>0.05)$, indicating that it does not require activation of the glial cystine-GLU antiporter. It is noteworthy, however, that CPG did cause a transient increase in basal (prestress) GLU at $\sim 20$ min following the start of drug 
application. In the PFC, CPG has been reported to act also as a competitive $\mathrm{mGlu}_{1}$ receptor antagonist (Baker et al., 2002; Melendez and Kalivas, 2003; Melendez et al., 2005) but also displays agonist (Hayashi et al., 1994; Baker et al., 2002) and antagonist (Thomsen et al., 1994) properties at $\mathrm{mGlu}_{2 / 3}$ receptors in other preparations. The transient CPG effect seen before stress is perhaps best explained by its action at $\mathrm{mGlu}_{2 / 3}$ receptors. Specifically, decreased cystine-GLU antiporter activity would result in reduced $\mathrm{mGlu}_{2 / 3}$ stimulation that would in turn lead to a transient increase in GLU release. A direct, antagonist action of CPG at $\mathrm{mGlu}_{2 / 3}$ receptors could also account for the transient increase in GLU levels. Additionally, activation of $\mathrm{mGlu}_{2 / 3}$ receptors on GABA interneurons has been reported to inhibit GABA release in the cerebellum (Mitchell and Silver, 2000) and nucleus tractus solitarii (Chen and Bonham, 2005). Thus, it is also conceivable that CPG could transiently stimulate GLU release as an indirect consequence of its inhibitory action on GABA transmission.

\section{Effects of left versus right PFC} excitotoxic lesions on the contralateral GLU stress response

The histological analysis (Fig. 4A,B) revealed damage characterized by neuronal loss, atrophy, and cavitation; no evidence of such damage was seen in sham-lesioned animals. While damage was clearly confined to either the left or right PFC, there was some between-animal variability in the extent of the lesions; in many animals, tissue damage was restricted mostly to the IL-PFC and the ventral portion of the PLPFC, but in several cases, neuronal loss was also observed in the dorsal PL-PFC, which occasionally extended into the cingulate cortex. When compared to shamlesioned animals, the PFC GLU response to stress was significantly attenuated in animals with ibotenic acid lesions to the opposite PFC (Fig. 4C, group $\times$ time interaction: $F_{(13,156)}=2.89, p<0.001$; and Fig. $4 D$, group $\times$ time interaction: $\left.F_{(13,156)}=7.10, p<0.0001\right)$; poststress GLU levels in lesioned animals tended to remain slightly (at times significantly) elevated over those of sham controls. Although the left and right PFC GLU stress responses were similarly attenuated by lesions to the opposite hemisphere, post hoc analysis revealed subtle yet significant hemispheric differences. Thus, whereas lesions to the left PFC significantly attenuated the right PFC GLU stress response throughout the 20 min tail-pinch episode $(p<0.01, p<0.05)$, right PFC lesions significantly attenuated the left PFC GLU response only during the first $10 \mathrm{~min}$ of the stress period $(p<0.01)$. On close inspection, however, this apparent hemispheric difference in lesion effects is likely due to the greater variability of the left PFC GLU stress response in the sham-lesioned animals. In addition, when compared to the respective sham controls, prestress PFC GLU levels were found to be higher in lesioned animals (Fig. 4D, inset). The magnitude of this effect was hemisphere dependent; that is, in left-lesioned animals, prestress GLU levels in right PFC were elevated by $<10 \%$ over those of sham controls (sham: $0.572 \mathrm{pmol} / \mu \mathrm{l} \pm 0.0167$ vs lesioned: $0.627 \mathrm{pmol} / \mu \mathrm{l} \pm$ $0.0277)$, but in right-lesioned animals, prestress GLU levels in left PFC were significantly elevated $(p<0.05)$ by almost $30 \%$ over those of sham controls (sham: $0.553 \mathrm{pmol} / \mu \mathrm{l} \pm 0.0285$ vs lesioned: 0.705 $\mathrm{pmol} / \mu \mathrm{l} \pm 0.0580$ ). Although intriguing, the functional significance of this finding is unclear, particularly in view of the fact that the basal GLU levels in the left versus right PFC of lesioned animals did not differ.

\section{Effects of left PFC $\mathrm{mGlu}_{2 / 3}$ receptor activation on the right PFC GLU stress response}

When compared to vehicle, LY379268 $(10 \mathrm{nmol})$ significantly attenuated the right PFC GLU stress response (Fig. 5) (treatment $\times$ time interaction: $\left.F_{(14,70)}=5.48, p<0.0001\right)$. Post hoc analysis confirmed that, following LY379268, GLU dialysate levels were significantly lower at times 0,10 , and 20 min than those seen following the vehicle treatment $(p<0.05)$; although not statistically significant, GLU levels during tail-pinch stress fol- 


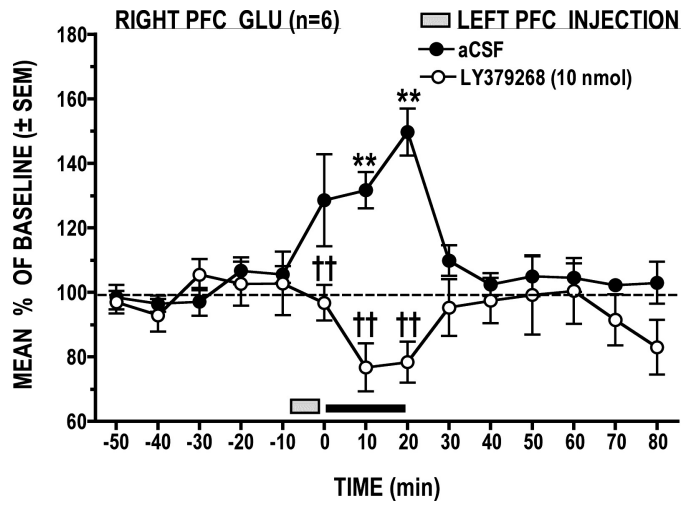

Figure 5. Local left PFC application of the $\mathrm{mGlu}_{2 / 3}$ receptor agonist LY379268 produced a stress-dependent decrease in right PFC GLU levels. ${ }^{* *} p<0.01$ versus prestress baseline; ${ }^{\mathrm{H}} p<0.01$ versus time-matched vehicle control.

A

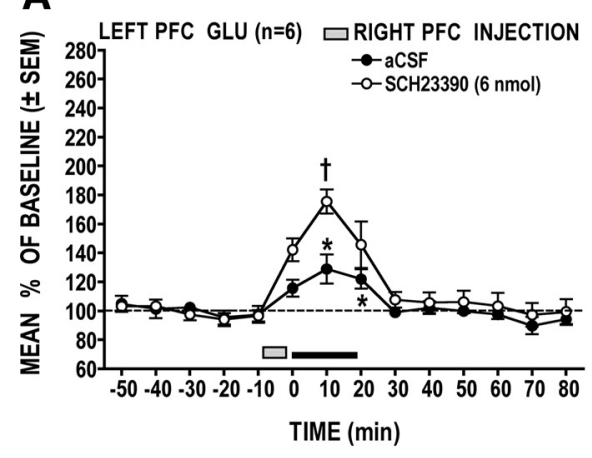

C

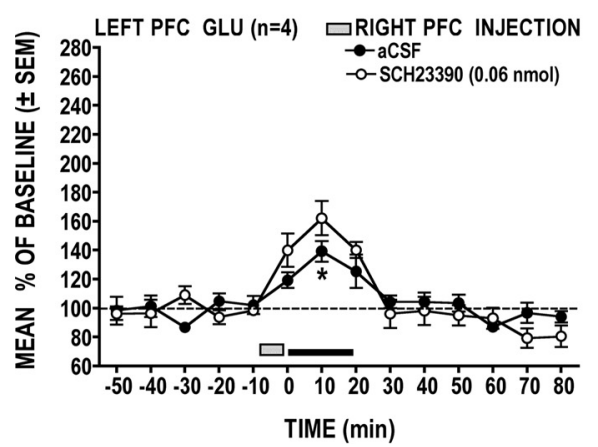

\section{B}

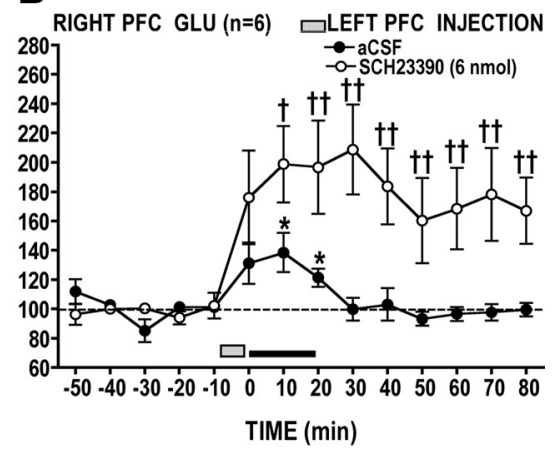

D

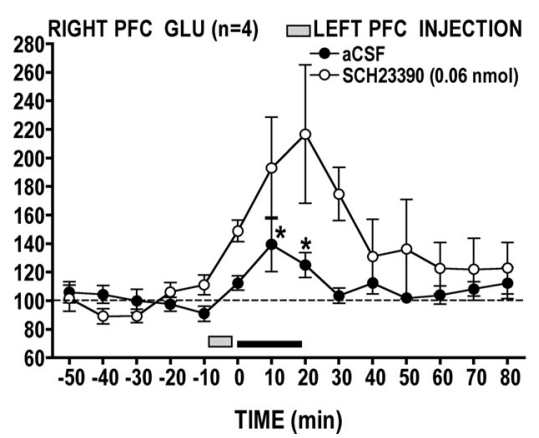

Figure 6. $A-D$, Effects of unilateral PFC $D_{1}$ receptor blockade on the contralateral PFC GLU response to stress. $A, B$, At the higher dose, $\mathrm{SCH} 23390$ injected into the left PFC produced a potent, long-lasting enhancement of the right PFC GLU stress response $(\boldsymbol{B})$, but when applied to the right PFC, the same treatment produced a comparatively weaker effect on the left PFC GLU response $(\boldsymbol{A})$. C, D, When injected into the left PFC, a lower dose of SCH23390 still produced a noticeable but shorter-lasting (nonsignificant) potentiation of the right PFC GLU stress response (D). Right PFC application of the low dose of SCH23390 had a negligible effect on the left PFC GLU response (C). ${ }^{*} p<0.05$ versus prestress baseline; ${ }^{\dagger} p<0.05,{ }^{\dagger \dagger} p<0.01$ versus time-matched vehicle control.

lowing LY379268 were noticeably lower than those seen before injection and following stress.

\section{Effects of left versus right $P F C D_{1}$ receptor blockade on the} contralateral GLU stress response

Figure 6, $A$ and $B$, shows that the PFC GLU stress response was significantly potentiated following local application of SCH23390 (6 $\mathrm{nmol}$ ) in the opposite PFC and that the magnitude of this effect was hemisphere dependent (hemisphere $\times$ treatment $\times$ time interaction: $\left.F_{(14,140)}=2.18, p=0.0114\right)$. Under the control (vehicle) condition, tail-pinch stress significantly increased $(p<$
0.05 at 10 and $20 \mathrm{~min}$ ) GLU to comparable levels in the left and right PFC. Local $D_{1}$ receptor blockade in the left PFC resulted in a significant $(p<0.05)$ long-lasting potentiation of the right PFC GLU stress response (Fig. $6 \mathrm{~B}$ ). However, the same treatment apdo the right $\mathrm{PFC}$ produced a relatively modest and shortlasting potentiation of the left PFC GLU stress response (Fig. 6A)

The prolonged potentiation of the right PFC GLU stress response produced by SCH23390 administration into the left PFC raised the possibility that the main effect of this treatment was to elevate basal levels of GLU, independently of the stressor. To rule out this possibility, a separate group of four animals was prepared to examine the right PFC GLU stress response following left PFC microinjections of a 100-fold lower dose of SCH23390 (0.06 $\mathrm{nmol}$ ). As can be seen in Figure 6D, this low dose of SCH23390 resulted in a similar, albeit nonsignificant, potentiation of the right PFC GLU stress response. Importantly, though, this effect was transient, with GLU levels returning to basal values within $20 \mathrm{~min}$ after stress. When applied to the right PFC of a separate group of animals $(n=$ 4), the same low dose of SCH23390 resulted in a slight nonsignificant potentiation of left PFC GLU stress response (Fig. 6C).

\section{Effects of left PFC $\alpha_{1}$-adrenoreceptor blockade on the right PFC GLU stress response}

Local application of BENOX (10 nmol) into the left PFC significantly attenuated the GLU stress response in the right PFC (Fig. 7) (treatment $\times$ time interaction: $\left.F_{(14,84)}=3.46, p=0.002\right)$; post hoc analysis revealed that this effect was significant at $10 \mathrm{~min}$ into the stress period $(p<0.01)$ Under the vehicle condition, tail-pinch stress significantly elevated right PFC GLU above baseline at $10(p<0.01)$ and $20(p<0.05) \mathrm{min}$. Following BENOX, however, GLU levels during the $20 \mathrm{~min}$ stress period did not differ significantly $(p>0.05)$ from prestress levels, and while poststress GLU levels appeared to be elevated, this effect was not significant $(p>0.05)$.

\section{Effects of left PFC GABA B $_{B}$ receptor activation on the right PFC GLU} stress response

Local baclofen $(10 \mathrm{nmol})$ application into the left PFC significantly potentiated the GLU stress response in the right PFC (Fig. 8) (treatment $\times$ time interaction: $F_{(14,70)}=2.20 p=0.016$ ); post hoc analysis revealed that this effect was significant after 20 min of stress $(p<0.05)$. Poststress GLU levels remained significantly elevated above basal levels for $30 \mathrm{~min}$ following the cessation of tail pinch stress $(p<0.05)$.

\section{Discussion}

\section{Origin of the PFC GLU stress response}

Our findings indicate that the PFC GLU stress response reflects, at least in part, activation of GLU-containing neurons located in the opposite hemisphere and, thus, implicate callosal neurons in 


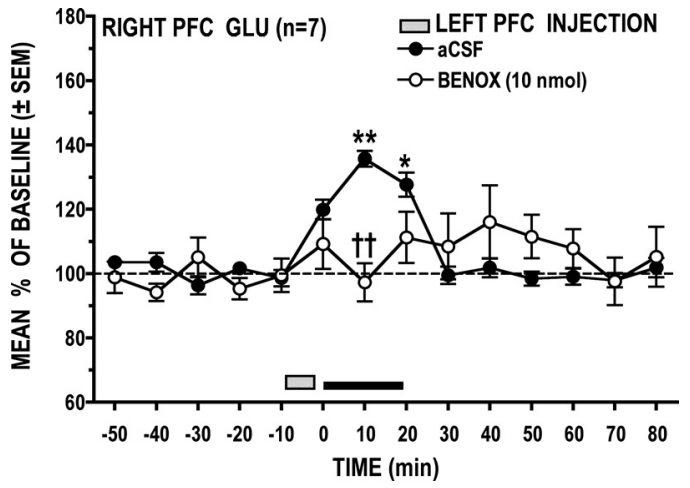

Figure 7. Local left PFC application of the $\alpha_{1}$-adrenoreceptor antagonist BENOX significantly attenuated the right PFC GLU stress response. ${ }^{*} p<0.05,{ }^{* *} p<0.01$ versus prestress baseline; ${ }^{\text {t† }} p<0.01$ versus time-matched vehicle control.

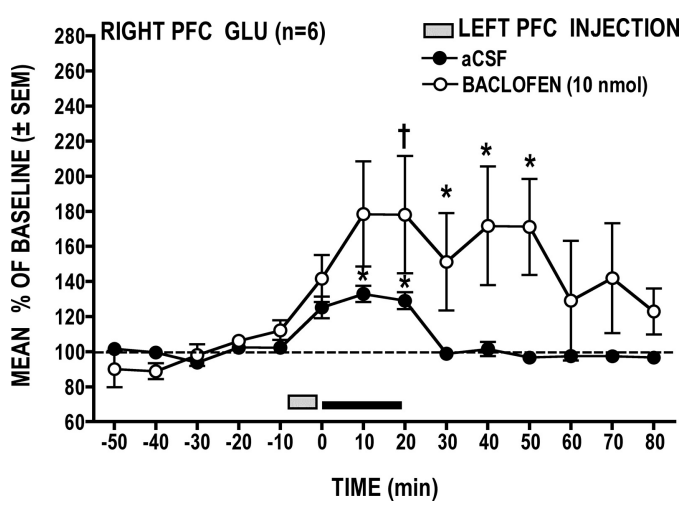

Figure 8. Local left $\mathrm{PFC}$ application of the $\mathrm{GABA}_{\mathrm{B}}$ receptor agonist baclofen significantly potentiated the right PFC GLU stress response. ${ }^{*} p<0.05$ versus prestress baseline; ${ }^{\dagger} p<0.01$ versus time-matched vehicle control.

PFC-mediated responses to stressors. A perennial question is whether this GLU response originates from neurons or glial cells; basal and stressed-induced increases in PFC GLU levels are reported to be insensitive (Hashimoto et al., 1995; Timmerman and Westerink, 1997) or partially sensitive (Moghaddam, 1993) to sodium channel blockade. In the present study, TTX had little effect on basal GLU levels but practically abolished the GLU stress response. Stress-induced GLU increases were abolished also when perfusate $\mathrm{Ca}^{2+}$ was omitted but were unaffected by glial cystine-GLU transporter blockade. Thus, although a glial contribution cannot be ruled out entirely, based on these criteria and the fact that the PFC GLU stress response was attenuated following excitotoxic lesions to the opposite hemisphere and was sensitive to contralateral drug injections, we conclude that stress-induced increases in PFC GLU are due mostly to increased neuronal release of the transmitter.

\section{Effects of excitotoxic lesions}

That the GLU response to stress was profoundly diminished by excitotoxic lesions to the opposite hemisphere is surprising because it suggests that other known GLU inputs to PFC do not contribute significantly to the GLU stress response. Such a possibility is difficult to envisage, particularly in the case of the basolateral amygdala (BLA). In addition to receiving a stressresponsive DA input (Inglis and Moghaddam, 1999), the BLA shares reciprocal GLU-containing connections with the PFC
(McDonald, 1991, 1996; Pinto and Sesack, 2008) and has been implicated in processing fear responses (Goldstein et al., 1996; Anglada-Figueroa and Quirk, 2005; Likhtik et al., 2005; Malin and McGaugh, 2006). Furthermore, it remains that stress did reliably elicit, in lesioned animals, small yet prolonged increases in GLU. It is therefore possible that activation of other PFC GLU inputs is responsible for this residual increase in transmitter levels. In considering this possibility, it is important to keep in mind that the poor temporal (and spatial) resolution of microdialysis precludes drawing any conclusions on the functional significance of this activation. Such protracted increases in GLU might just as well reflect the integrated sum of multiple bursts of transmitter release as it would a small sustained elevation of transmitter levels.

\section{Role of $\mathrm{mGlu}_{2 / 3}$ receptors}

Unilateral PFC $\mathrm{mGlu}_{2 / 3}$ receptor activation blocked the opposite PFC GLU stress response but also caused GLU to decrease below basal levels during the stress episode. This suggests that stressinduced activation of interhemispheric GLU transmission is itself regulated by GLU, although the mechanism by which this occurs is unclear. Activation of presynaptic $\mathrm{mGlu}_{2 / 3}$ receptors inhibits GLU release (Kilbride et al., 1998; Cartmell and Schoepp, 2000; Schoepp, 2001), and this should result in less activation of callosal neurons projecting to the opposite PFC. However, the fact that LY379268 caused a stress-dependent reduction in GLU suggests a more complex mechanism. While LY379268 might directly influence the excitability of callosal neurons via postsynaptic $\mathrm{mGlu}_{2 / 3}$ receptors (Sekizawa et al., 2009), there is evidence that GLU can inhibit GABA release by acting at presynaptic $\mathrm{mGlu}_{2 / 3}$ receptors (Mitchell and Silver, 2000; Chen and Bonham, 2005). Moreover, local $\mathrm{mGlu}_{2 / 3}$ receptor activation inhibits stress-induced increases in PFC NE but has no effect on the PFC DA stress response (Swanson et al., 2004). Elucidating how activation of heterosynaptic $\mathrm{mGlu}_{2 / 3}$ receptors might result in such stressdependent decreases in PFC GLU will require additional experimentation. Still, evidence of $\mathrm{mGlu}_{2 / 3}$ receptors on GABA and $\mathrm{NE}$ terminals is significant; given that the GLU stress response was sensitive to $\mathrm{GABA}_{\mathrm{B}}$ receptor activation and $\alpha_{1}$-adrenoreceptor blockade, it suggests that $\mathrm{mGlu}_{2 / 3}$ receptor-mediated modulation of PFC GABA and NE release plays a role in regulating stressinduced activation of callosal neurons.

\section{Involvement of NE and GABA}

Unilateral $\alpha_{1}$-adrenoreceptor blockade attenuated the opposite PFC GLU stress response; this effect was followed by a small, sustained increase in GLU suggesting that the drug acted at multiple sites. While $\alpha_{1}$-adrenoreceptors are mostly postsynaptic, some might also be located presynaptically (Nakadate et al., 2006), and although $\alpha_{1}$-adrenoreceptor activation was initially reported to increase EPSCs in PFC pyramidal neurons (Marek and Aghajanian,1999), recent evidence suggests instead that it suppresses GLU-, AMPA-, and NMDA-induced EPSCs (Kobayashi et al., 2009). Furthermore, locally applied NE increases PFC DA levels, an effect that is inhibited by local $\alpha_{1}$-adrenoreceptor blockade (Pan et al., 2004). Thus it is presently unclear whether the effects of benoxathian were mediated directly by $\alpha_{1}$-adrenoreceptors on callosal neurons or indirectly via a DA-dependent mechanism.

The PFC GLU stress response was facilitated by contralateral $\mathrm{GABA}_{\mathrm{B}}$ receptor activation, suggesting an indirect action of GABA on the activity of callosal neurons; the direct action of GABA on pyramidal neurons is mediated primarily by $\mathrm{GABA}_{\mathrm{A}}$ 
receptors. Given that baclofen and $D_{1}$ receptor blockade (with SCH23390) similarly enhanced the GLU stress response and that local $\mathrm{GABA}_{\mathrm{B}}$ receptor activation inhibits PFC DA release (Santiago et al., 1993; Balla et al., 2009) and the PFC DA stress response (Doherty and Gratton, 1999), it is conceivable that baclofen facilitated the PFC GLU stress response as a consequence of inhibiting stress-induced DA release in the opposite hemisphere. As discussed below, an interaction between GABA- and DAsensitive mechanisms is likely to account also for the enhanced GLU stress response produced by SCH23390.

\section{Role of $D_{1}$ receptors}

Our data suggest that DA exerts a $\mathrm{D}_{1}$ receptor-mediated inhibitory influence on PFC callosal neurons. This control is asymmetrical in that the left PFC DA input exerts a stronger influence on the contralateral GLU stress response than does the right PFC DA input. $\mathrm{D}_{1}$ and $\mathrm{D}_{2}$ receptors are located on PFC pyramidal neurons, including callosal neurons, most of which also express NMDA receptors (Kruse et al., 2009; Santana et al., 2009). Electrophysiological evidence indicates that $\mathrm{D}_{1}$ receptor activation potentiates NMDA receptor-mediated increases in cell excitability, while activation of $\mathrm{D}_{2}$ receptors has the opposite effect (Yang and Seamans, 1996; Trantham-Davidson et al., 2004; Tseng and O’Donnell, 2004; Tseng et al., 2006). In light of this, SCH23390 would presumably have prevented the synergistic effect of concurrent $D_{1}$ and NMDA receptor activation on the excitability of callosal neurons. If this was indeed the case, then blocking $\mathrm{D}_{1}$ receptors on callosal neurons should not have potentiated, as it did, the contralateral PFC GLU stress response; a dampened GLU stress response would be expected instead, assuming that DA released during stress activated only $\mathrm{D}_{2}$ receptors. Another possibility is that the effect of SCH23390 was mediated indirectly via $\mathrm{D}_{1}$ receptors located on GABA interneurons. Activation of these receptors causes a prolonged increase in IPSCs in PFC pyramidal neurons, ostensibly as a result of increasing the excitability of GABA interneurons; in contrast, activation of $\mathrm{D}_{2}$ receptors on GABA interneurons appears to diminish PFC pyramidal cell IPSCs, presumably as a result of inhibiting GABA transmission (Seamans et al., 2001; Trantham-Davidson et al., 2004). Thus, one possible consequence of GABA interneuron $D_{1}$ receptor blockade might have been to unmask the indirect disinhibitory effect of GABA interneuron $\mathrm{D}_{2}$ receptor activation (by DA released during stress) on pyramidal cell activity.

\section{Asymmetric modulation of the GLU stress response by DA} That interhemispheric modulation of the PFC GLU stress response by DA is asymmetric is consistent with evidence that the left and right PFC DA inputs are activated to different degrees depending on the stressor and play functionally distinct but complementary roles in the various responses (i.e., behavioral, endocrine, autonomic) engaged to counter the immediate and long-term effects of stressors. The PFC DA response to shortlasting stressors is typically biased toward the left hemisphere. However, activation of PFC DA transmission will shift from this initial left-brain bias to a right-brain bias in response to severe stressors or when exposure to such stressors becomes prolonged or is perceived as uncontrollable (Carlson et al., 1991, 1993; Sullivan and Szechtman, 1995; Berridge et al., 1999; Stalnaker et al., 2009). As proposed by Denenberg et al. (1986), the initial left-biased PFC DA response might mediate preemptive responses to stressors before they become unmanageable and start engaging the right PFC mechanisms involved in activating phys- iological stress responses (Sullivan and Szechtman, 1995; Sullivan and Gratton, 1998, 1999, 2002b). However, activation of the right PFC would eventually come to predominate when, in the face of a prolonged and inescapable stressor, the early left PFC-mediated responses prove to be ineffective. Under these conditions, the rightbiased increase in PFC DA transmission might serve to prevent the negative consequences of sustained right PFC activity. Indeed, impaired right PFC DA function is typically associated with maladaptive responses to stressors and increased vulnerability to stressrelated disorders (Kalin et al., 1998; Stefanatos and Wasserstein, 2001; Sullivan and Gratton, 2002a; Gratton and Sullivan, 2005). We can only speculate as to mechanism(s) underlying the asymmetric effects of SCH23390 on stress-induced activation of interhemispheric GLU transmission. It is reasonable to assume, however, that these reflect left versus right hemispheric differences in the cellular and subcellular distributions of $\mathrm{D}_{1}$ and $\mathrm{D}_{2}$ receptors and of other receptor mechanisms known to regulate the excitability of PFC callosal neurons.

\section{Conclusions}

The present findings indicate that stressors stimulate PFC GLU transmission in one hemisphere as a consequence of activating or disinhibiting pyramidal neurons located in the opposite hemisphere. While our data do not preclude a role for other GLU inputs to PFC, they do indicate that an important component of the PFC GLU stress response represents increased interhemispheric communication by callosal neurons. Together, these findings implicate callosal neurons in the circuitry regulating the noted hemispheric specialization of PFC-mediated responses to stressors.

\section{References}

Abercrombie ED, Keefe KA, DiFrischia DS, Zigmond MJ (1989) Differential effect of stress on in vivo dopamine release in striatum, nucleus accumbens, and medial frontal cortex. J Neurochem 52:1655-1658.

Anglada-Figueroa D, Quirk GJ (2005) Lesions of the basal amygdala block expression of conditioned fear but not extinction. J Neurosci 25:9680-9685.

Bagley J, Moghaddam B (1997) Temporal dynamics of glutamate efflux in the prefrontal cortex and in the hippocampus following repeated stress: effects of pretreatment with saline or diazepam. Neuroscience 77:65-73.

Baker DA, Xi ZX, Shen H, Swanson CJ, Kalivas PW (2002) The origin and neuronal function of in vivo nonsynaptic glutamate. J Neurosci 22:9134-9141.

Balla A, Nattini ME, Sershen H, Lajtha A, Dunlop DS, Javitt DC (2009) $\mathrm{GABAB} / \mathrm{NMDA}$ receptor interaction in the regulation of extracellular dopamine levels in rodent prefrontal cortex and striatum. Neuropharmacology 56:915-921.

Berridge CW, Mitton E, Clark W, Roth RH (1999) Engagement in a non-escape (displacement) behavior elicits a selective and lateralized suppression of frontal cortical dopaminergic utilization in stress. Synapse 32:187-197.

Brake WG, Sullivan RM, Gratton A (2000) Perinatal distress leads to lateralized medial prefrontal cortical dopamine hypofunction in adult rats. J Neurosci 20:5538-5543.

Carlson JN, Fitzgerald LW, Keller RW Jr, Glick SD (1991) Side and region dependent changes in dopamine activation with various durations of restraint stress. Brain Res 550:313-318.

Carlson JN, Fitzgerald LW, Keller RW Jr, Glick SD (1993) Lateralized changes in prefrontal cortical dopamine activity induced by controllable and uncontrollable stress in the rat. Brain Res 630:178-187.

Carr DB, Sesack SR (1998) Callosal terminals in the rat prefrontal cortex: synaptic targets and association with GABA-immunoreactive structures. Synapse 29:193-205. 
Carr DB, Sesack SR (2000) Dopamine terminals synapse on callosal projection neurons in the rat prefrontal cortex. J Comp Neurol 425:275-283.

Cartmell J, Schoepp DD (2000) Regulation of neurotransmitter release by metabotropic glutamate receptors. J Neurochem 75:889-907.

Chen CY, Bonham AC (2005) Glutamate suppresses GABA release via presynaptic metabotropic glutamate receptors at baroreceptor neurones in rats. J Physiol 562:535-551.

Denenberg VH, Gall JS, Berrebi A, Yutzey DA (1986) Callosal mediation of cortical inhibition in the lateralized rat brain. Brain Res 397:327-332.

Doherty MD, Gratton A (1999) Effects of medial prefrontal cortical injections of GABA receptor agonists and antagonists on the local and nucleus accumbens dopamine responses to stress. Synapse 32:288-300.

Finlay JM, Zigmond MJ, Abercrombie ED (1995) Increased dopamine and norepinephrine release in medial prefrontal cortex induced by acute and chronic stress: effects of diazepam. Neuroscience 64:619-928.

Goldstein LE, Rasmusson AM, Bunney BS, Roth RH (1996) Role of the amygdala in the coordination of behavioral, neuroendocrine, and prefrontal cortical monoamine responses to psychological stress in the rat. J Neurosci 16:4787-4798.

Gratton A, Sullivan RM (2005) Role of the prefrontal cortex in stress responsivity. In: Handbook of stress and the brain, Pt 1, The neurobiology of stress, Vol 15 (Steckler T, Kalin N, Reul JMHM, eds), pp 807-818. Amsterdam: Elsevier Science.

Hashimoto A, Oka T, Nishikawa T (1995) Extracellular concentration of endogenous free $\mathrm{D}$-serine in the rat brain as revealed by in vivo microdialysis. Neuroscience 66:635-643.

Hayashi Y, Sekiyama N, Nakanishi S, Jane DE, Sunter DC, Birse EF, Udvarhelyi PM, Watkins JC (1994) Analysis of agonist and antagonist activities of phenylglycine derivatives for different cloned metabotropic glutamate receptor subtypes. J Neurosci 14:3370-3377.

Inglis FM, Moghaddam B (1999) Dopaminergic innervation of the amygdala is highly responsive to stress. J Neurochem 72:1088-1094.

Kalin NH, Larson C, Shelton SE, Davidson RJ (1998) Asymmetric frontal brain activity, cortisol, and behavior associated with fearful temperament in rhesus monkeys. Behav Neurosci 112:286-292.

Karayannis T, Huerta-Ocampo I, Capogna M (2007) GABAergic and pyramidal neurons of deep cortical layers directly receive and differently integrate callosal input. Cereb Cortex 17:1213-1226.

Kilbride J, Huang LQ, Rowan MJ, Anwyl R (1998) Presynaptic inhibitory action of the group II metabotropic glutamate receptor agonists, LY354740 and DCG-IV. Eur J Pharmacol 356:149-157.

Kobayashi M, Kojima M, Koyanagi Y, Adachi K, Imamura K, Koshikawa N (2009) Presynaptic and postsynaptic modulation of glutamatergic synaptic transmission by activation of a1- and b-adrenoceptors in layer v pyramidal neurons of rat cerebral cortex. Synapse 63:269-281.

Kruse MS, Prémont J, Krebs M-O, Jay TM (2009) Interaction of dopamine D1 and NMDA NR1 receptors in rat prefrontal cortex. Eur Neuropsychopharmacol 19:296-304.

Likhtik E, Pelletier JG, Paz R, Paré D (2005) Prefrontal control of the amygdala. J Neurosci 25:7429-7437.

Malin EL, McGaugh JL (2006) Differential involvement of the hippocampus, anterior cingulate cortex, and basolateral amygdala in memory for context and footshock. Proc Natl Acad Sci U S A 103:1959-1963.

Marek GJ, Aghajanian GK (1999) 5-HT2A receptor or alpha1-adrenoceptor activation induces excitatory postsynaptic currents in layer $\mathrm{V}$ pyramidal cells of the medial prefrontal cortex. Eur J Pharmacol 367:197-206.

McDonald AJ (1991) Organization of amygdaloid projections to the prefrontal cortex and associated striatum in the rat. Neuroscience 44:1-14.

McDonald AJ (1996) Glutamate and aspartate immunoreactive neurons of the rat basolateral amygdala: colocalization of excitatory amino acids and projections to the limbic circuit. J Comp Neurol 365:367-379.

Melendez RI, Kalivas PW (2003) Metabotropic glutamate receptor regulation of extracellular glutamate levels in the prefrontal cortex. Ann N Y Acad Sci 1003:443-444.

Melendez RI, Vuthiganon J, Kalivas PW (2005) Regulation of extracellular glutamate in the prefrontal cortex: focus on the cystine glutamate exchanger and group I metabotropic glutamate receptors. J Pharmacol Exp Ther 314:139-147.

Mitchell SJ, Silver RA (2000) Glutamate spillover suppresses inhibition by activating presynaptic mGluRs. Nature 404:498-502.
Moghaddam B (1993) Stress preferentially increases extraneuronal levels of excitatory amino acids in the prefrontal cortex: comparison to hippocampus and basal ganglia. J Neurochem 60:1650-1657.

Nakadate K, Imamura K, Watanabe Y (2006) Cellular and subcellular localization of a1-adrenoceptors in the rat visual cortex. Neuroscience 141:1783-1792.

NicNiocaill B, Gratton A (2007) Medial prefrontal cortical alpha ${ }_{1}$ adrenoreceptor modulation of the nucleus accumbens dopamine response to stress in Long-Evans rats. Psychopharmacology 191:835-842.

Pan WHT, Yang S-Y, Lin S-K (2004) Neurochemical interaction between dopaminergic and noradrenergic neurons in the medial prefrontal cortex. Synapse 53:44-52.

Paxinos G, Watson C (1996) The rat brain in stereotaxic coordinates. New York: Academic.

Pinto A, Sesack SR (2008) Ultrastructural analysis of prefrontal cortical inputs to the rat amygdala: spatial relationships to presumed dopamine axons and D1 and D2 receptors. Brain Struct Funct 213:159-175.

Santana N, Mengod G, Artigas F (2009) Quantitative analysis of the expression of dopamine D1 and D2 receptors in pyramidal and GABAergic neurons of the rat prefrontal cortex. Cerebral Cortex 19:849-860.

Santiago M, Machado A, Cano J (1993) Regulation of the prefrontal cortical dopamine release by $\mathrm{GABA}_{\mathrm{A}}$ and $\mathrm{GABA}_{\mathrm{B}}$ receptor agonists and antagonists. Brain Res 630:28-31.

Schoepp DD (2001) Unveiling the functions of presynaptic metabotropic glutamate receptors in the central nervous system. J Pharmacol Exp Ther 299:12-20.

Seamans JK, Gorelova N, Durstewitz D, Yang CR (2001) Bidirectional dopamine modulation of GABAergic inhibition in prefrontal cortical pyramidal neurons. J Neurosci 21:3628-3638.

Sekizawa S, Bechtold AG, Tham RC, Bonham AC (2009) A novel postsynaptic group II metabotropic glutamate receptor role in modulating baroreceptor signal transmission. J Neurosci 29:11807-11816.

Stalnaker TA, España RA, Berridge CW (2009) Coping behavior causes asymmetric changes in neuronal activation in the prefrontal cortex and amygdale. Synapse 63:82-85.

Steciuk M, Kram M, Kramer GL, Petty F (2000) Immobilization-induced glutamate efflux in medial prefrontal cortex: blockade by (+)-Mk-801, a selective NMDA receptor antagonist. Stress 3:195-199.

Stefanatos GA, Wasserstein J (2001) Attention deficit/hyperactivity disorder as a right hemisphere syndrome. Selective literature review and detailed neuropsychological case studies. Ann N Y Acad Sci 931:172-195.

Stevenson CW, Sullivan RM, Gratton A (2003) Effects of basolateral amygdala dopamine depletion on the nucleus accumbens and medial prefrontal cortical dopamine responses to stress. Neuroscience 116:285-293.

Sullivan RM (2004) Hemispheric asymmetry in stress processing in rat prefrontal cortex and the role of mesocortical dopamine. Stress 7:131-143.

Sullivan RM, Gratton A (1998) Relationships between stress-induced increases in medial prefrontal cortical dopamine and plasma corticosterone levels in rats: role of cerebral laterality. Neuroscience 83:81-91.

Sullivan RM, Gratton A (1999) Lateralized effects of medial prefrontal cortex lesions on neuroendocrine and autonomic stress responses in rats. J Neurosci 19:2834-2840.

Sullivan RM, Gratton A (2002a) Behavioral effects of excitotoxic lesions of ventral medial prefrontal cortex in the rat are hemisphere-dependent. Brain Res 927:69-79.

Sullivan RM, Gratton A (2002b) Prefrontal cortical regulation of hypothalamicpituitary-adrenal function in the rat and implications for psychopathology: side matters. Psychoneuroendocrinology 27:99-114.

Sullivan RM, Szechtman H (1995) Asymmetrical influence of mesocortical dopamine depletion on stress ulcer development and subcortical dopamine systems in rats: implications for psychopathology. Neuroscience 65:757-766.

Swanson CJ, Perry KW, Schoepp DD (2004) The mGlu2/3 receptor agonist, LY354740, blocks immobilization-induced increases in noradrenaline and dopamine release in the rat medial prefrontal cortex. J Neurochem 88:194-202.

Thierry AM, Tassin JP, Blanc G, Glowinski J (1976) Selective activation of mesocortical DA system by stress. Nature 263:242-244.

Thomsen C, Boel E, Suzdak PD (1994) Actions of phenylglycine analogs at 
subtypes of the metabotropic glutamate receptor family. Eur J Pharmacol 267:77-84.

Timmerman W, Westerink BHC (1997) Brain microdialysis of GABA and glutamate: what does it signify? Synapse 27:242-261.

Timmerman W, Cisci G, Nap A, de Vries JB, Westerink BH (1999) Effects of handling on extracellular levels of glutamate and other amino acids in various areas of the brain measured by microdialysis. Brain Res 833: $150-160$.

Trantham-Davidson H, Neely LC, Lavin A, Seamans JK (2004) Mechanisms underlying differential $\mathrm{D}_{1}$ versus $\mathrm{D}_{2}$ dopamine receptor regulation of inhibition in prefrontal cortex. J Neurosci 24:10652-10659.

Tseng KY, O’Donnell P (2004) Dopamine-glutamate interactions control- ling prefrontal cortical pyramidal cell excitability involves multiple signaling mechanisms. J Neurosci 24:5131-5139.

Tseng KY, Mallet N, Toreson KL, Le Moine C, Gonon F, O’Donnell P (2006) Excitatory response of prefrontal cortical fast-spiking interneurons to ventral tegmental area stimulation in vivo. Synapse 59:412-417.

van der Zeyden M, Oldenziel WH, Rea K, Cremers TI, Westerink BH (2008) Microdialysis of GABA and glutamate: analysis, interpretation and comparison with microsensors. Pharmacol Biochem Behav 90:135147.

Yang CR, Seamans JK（1996） Dopamine D1 receptor actions in layers V-VI rat prefrontal cortex neurons in vitro. Modulation of dendritic-somatic signal integration. J Neurosci 16:1922-1935. 